Alan H. Morris

\title{
Exciting new ECMO technology awaits compelling scientific evidence for widespread use in adults with respiratory failure
}

Received: 16 November 2011

Accepted: 16 November 2011

Published online: 7 December 2011

(C) Copyright jointly held by Springer and ESICM 2011

This editorial refers to the article available at: doi:10.1007/s00134-011-2439-2.

\author{
A. H. Morris ( \\ Pulmonary/Critical Care Division, \\ Intermountain Medical Center (University of Utah), \\ Salt Lake City, UT 84157, USA \\ e-mail: Alan.Morris@imail.org
}

MacLaren et al. [1] discuss the exciting potential offered by extracorporeal support, including extracorporeal membrane oxygenation (ECMO). Many uses of ECMO have recently been discussed. These include a technically advanced means of transporting patients with severe respiratory failure [2] and a treatment for acute respiratory distress syndrome (ARDS) following novel H1N1 influenza infection [3]. Extracorporeal support remains an exciting domain of investigation, development and clinical application. Innovations, such as IVOX, abound among developers and practitioners of extracorporeal support [4]. Dr. Bartlett has been a consistent leader and innovator in this field.

MacLaren et al. [1] make impressive arguments, and their illustrations are clear and compelling. Their Fig. 6 is a striking example of the advances/changes in clinical care. The new extracorporeal circuits they nicely describe are clearly much simpler, easier to use, and appear more safe than those used in the past. Importantly, they appear safer than those used in the two past clinical trials that adhered to accepted experimental standards $[5,6]$. This raises legitimate questions about the current value of the results of those two older clinical trials. These legitimate questions should be answered with new clinical trials that adhere to accepted experimental standards. The authors clearly indicate that major advances in both extracorporeal circuitry and clinical care have taken place, since the technology of these two older clinical trials was introduced. I believe it is time for these advances to be matched by similar advances in extracorporeal clinical trials. Rigorous clinical trials with modern technology will likely provide results that answer crucial questions about "in whom, how, and when" extracorporeal support should be applied.

The experimental design of two-group randomized controlled clinical trials has not changed substantially since the older trials were completed $[5,6]$. In the absence of credible new clinical trial results, we have no better information to guide decisions about widespread use of extracorporeal support than that provided by the two past clinical trials that adhered to accepted experimental standards $[5,6]$. Some clinicians hold strong beliefs in the efficacy of ECMO support for patients with severe ARDS. Dr. MacLaren [7] articulately expressed these beliefs in a recent letter. Such strong beliefs are not new. In 1984 and 1985 Gattinoni et al. [8] reported a dramatic increase in survival with use of low frequency positive pressure ventilation with extracorporeal carbon dioxide removal (LFPPV-ECCO2R) (using veno-venous support). My colleagues and I conducted a randomized controlled clinical trial with the expectation that LFPPV-ECCO2R was likely to be a significant treatment advance (from our published discussion: "...we concluded from published reports that there was about a 0.5 prior probability that LFPPV-ECCO2R was a superior therapy for ARDS" [6]). However, we did not detect a survival advantage of LFPPV_ECCO2R. Gattinoni et al., in a letter to the editor, replied that the LFPPV_ECCO2R technique was not yet optimized and the technique not yet ready for a clinical trial (see letters to the editor in [6]). We asked, in a reply letter, how it could be known that the LFPPVECCO2R technique was beneficial (the conclusion of the strong believers) when the technique was not yet 
adequately evolved to perform a clinical trial? I cite these published exchanges only to indicate that current uncertainty about the role of extracorporeal support is an old one. It will only be resolved by new and properly conducted randomized controlled clinical trials. Such a clinical trial has not yet been done. The recent clinical trial in the UK did not adhere to accepted experimental standards $[9,10]$. The uncertainty might also be resolved by spectacular and compelling observational results, e.g., like those observed with the initial treatment of pneumococcal pneumonia with penicillin in the 1940s. However, this is unlikely. We will not likely encounter observational results more compelling that those of Gattinoni et al. [8] in 1984 and 1985 when they reported a $77 \%$ survival of patients meeting the 1970s ECMO criteria. Survival of such patients had to that point been consistently $10 \%$ in Boston and Salt Lake City centers, two of the original NIH ECMO clinical trial centers [5].

In response to previous publications [11, 12], Dr. MacLaren [7] raised three issues: ECMO must be correctly applied; ECMO must be applied to the appropriate patient; and finally that we need to define when, how, and in whom we can optimally use the technique. I believe MacLaren raised crucial issues that can only be defined with detailed methods for selection of patients, conduct of extracorporeal support, and management of important clinical interventions. Short of this, clinicians cannot know when, how, and in whom to optimally apply ECMO. For example, in the current publication, MacLaren et al. [1] indicate that patient complications continue to occur, uncertainties remain, and that "there are no effective means of confidently predicting recovery or death".

The alternative to credible clinical trial results is to accept at face value the claim of experts that their experience "managing adult patients on ECMO for refractory respiratory failure," or similar expressions, demonstrates, documents, and validates the efficacy of ECMO [7]. Unfortunately, such beliefs, no matter how strongly and sincerely held, are frequently proven to be invalid when formally tested using scientifically rigorous methods [13]. Experience can easily mislead due to the selective emphasis or recollection that characterizes human cognition. Past treatments that were enthusiastically supported and widely disseminated but subsequently shown to be of no value-or even harmful-include avoiding beta blockers in heart failure treatment; insulin for schizophrenia; vitamin $\mathrm{K}$ for myocardial infarction; hormone replacement therapy to prevent cardiovascular disease; flecainide for ventricular tachycardia; and immobilizaton of scaphoid bone fractures [14]. More recently we have been exposed to a change in the management of sepsis. Sepsis therapy with drotrecogin alfa $\left(\right.$ Xigris $\left.^{\circledR}\right)$ was recently interrupted by withdrawal of the drug by the manufacturer [15].

Noah et al. [3] resumed the ECMO dialog in a recent publication describing retrieval of $\mathrm{H} 1 \mathrm{~N} 1$ respiratory failure patients for ECMO in the UK. This publication elicited an editorial that echoed arguments raised by others, calling for more compelling data to support the efficacy of ECMO before ECMO is widely propagated for management of severe ARDS [16]. Roger Bone, 25 years ago, discussed some of the issues that made observational studies of extracorporeal support difficult to interpret [17]. These issues are still a problem and they are central to the controversy surrounding extracorporeal support today. I believe extracorporeal support is an exciting and promising technique. I think its clinical applications require a more firm scientific foundation than currently exists. Maclaren et al. have compellingly described the new ECMO technology. I hope this is followed by new and compelling evidence that the new technology has enabled us to reap the promised benefits of extracorporeal support.

\section{References}

1. MacLaren G, Combes A, Bartlett RH (2011) Contemporary extracorporeal membrane oxygenation for adult respiratory failure: life support in the new era. Intensive Care Med. doi: 10.1007/s00134-011-2439-2

2. Forrest P, Ratchford J, Burns B, Herkes R, Jackson A, Plunkett B, Torzillo P, Nair P, Granger E, Wilson M, Pye R (2011) Retrieval of critically ill adults using extracorporeal membrane oxygenation: an Australian experience. Intensive Care Med 37:824-830
3. Noah MA, Peek GJ, Finney SJ, Griffiths MJ, Harrison DA, Grieve R, Sadique MZ, Sekhon JS, McAuley DF, Firmin RK, Harvey C, Cordingley JJ, Price S, Vuylsteke A, Jenkins DP, Noble DW, Bloomfield R, Walsh TS, Perkins GD, Menon D, Taylor BL, Rowan KM (2011) Referral to an extracorporeal membrane oxygenation center and mortality among patients with severe 2009 influenza A(H1N1). JAMA 306(15):1659-1668

4. Mortensen J (1992) Intravascular oxygenator: a new alternative method for augmenting blood gas transfer in patients with acute respiratory failure. Artif Organs 16:75-82
5. Zapol WM, Snider MT, Hill JD, Fallat RJ, Bartlett RH, Edmunds LH, Morris AH, Peirce ECI, Thomas AN, Proctor HJ, Drinker PA, Pratt PC, Bagniewski A, Miller RG (1979) Extracorporeal membrane oxygenation in severe acute respiratory failure. JAMA 242:2193-2196 
6. Morris A, Wallace C, Menlove R, Clemmer T, Orme JJ, Weaver L, Dean N, Thomas F, East T, Suchyta M, Beck E, Bombino M, Sittig D, Böhm S, Hoffmann B, Becks H, Pace N, Butler S, Pearl J, Rasmusson B (1994) Randomized clinical trial of pressurecontrolled inverse ratio ventilation and extracorporeal CO2 removal for ARDS [erratum 1994;149(3, Pt 1):838, Letters to the editor $1995 ; 151(1): 255-256$, 1995;151(4):1269-1270, and 1997;156(3):1016-1017]. Am J Respir Crit Care Med 149:295-305

7. MacLaren G (2011) Evidence and experience in extracorporeal membrane oxygenation. Chest 139:965

8. Gattinoni L, Pesenti A, Caspani M, Pelizzola A, Mascheroni D, Marcolin R, Iapichino $\mathrm{G}$, Langer M, Agostoni A, Kolobow T, Melrose D, Damia G (1984) The role of total static lung compliance in the management of severe ARDS unresponsive to conventional treatment. Intensive Care Med 10:121-126
9. Peek G, Clemens F, Elbourne D, Firmin R, Hardy P, Hibbert C, Killer H, Mugford M, Thalanany M, Tiruvoipati R, Truesdale A, Wilson A (2006) CESAR: conventional ventilatory support vs extracorporeal membrane oxygenation for severe adult respiratory failure. BMC Health Serv Res 6:163. doi:10.1186/1472-6963-6-163

10. Peek GJ, Mugford M, Tiruvoipati R, Wilson A, Allen E, Thalanany MM, Hibbert CL, Truesdale A, Clemens F, Cooper N, Firmin RK, Elbourne D (2009) Efficacy and economic assessment of conventional ventilatory support versus extracorporeal membrane oxygenation for severe adult respiratory failure (CESAR): a multicentre randomised controlled trial. Lancet 374:1351-1363

11. Morris AH, Hirshberg E, Miller RR, Statler KD, Hite RD (2010)

Counterpoint: efficacy of extracorporeal membrane oxygenation in 2009 influenza $\mathrm{A}(\mathrm{H} 1 \mathrm{~N} 1)$. Chest 138:778-781

12. Morris AH, Hirshberg E, Miller RR, Statler KD, Hite RD, Hite RD (2010) Rebuttal from Dr. Morris et al. Chest 138:783-784
13. Morris A (2006) The importance of protocol-directed patient management for research on lung-protective ventilation. In: Dreyfuss D, Saumon G, Hubamyr R (eds) Ventilator-induced lung injury. Taylor \& Francis, New York, pp 537-610

14. Doust J, Mar CD (2004) Why do doctors use treatments that do not work? BMJ 328:474-475

15. FDA (2011) FDA drug safety communication: voluntary market withdrawal of Xigris [drotrecogin alfa (activated)] due to failure to show a survival benefit. Available via http://www.fda.gov/Drugs/DrugSafety/ ucm277114.htm. Accessed 25 Oct 2011

16. Checkley W (2011) Extracorporeal membrane oxygenation as a first-line treatment strategy for ARDS. JAMA 306(15):1703-1704

17. Bone R (1986) Extracorporeal membrane oxygenation for acute respiratory failure (Editorial). JAMA 256:910 